\title{
AiMT
}

Advances in Military Technology

Vol. 13, No. 1 (2018), pp. 47-58

ISSN 1802-2308, eISSN 2533-4123

DOI 10.3849/aimt.01214

\section{Experimental Investigation of CFRP Impact Toughness and Failure Modes}

\author{
O. Flášar* \\ University of Defence in Brno, Czech Republic \\ The manuscript was received on 22 September 2017 and was accepted \\ after revision for publication on 24 March 2018.
}

\begin{abstract}
:
The experimental investigation assesses the capability of Carbon Fibre Reinforced Plastics (CFRP) to absorb impact energy. The method is based on measuring impact toughness of unnotched beam specimens made of laminates with woven and unidirectional reinforcement in either cross-ply $[0 / 90]_{\mathrm{n}}$ or angle-ply $[ \pm 45]_{\mathrm{n}}$ orientation using impact pendulum testing machine. Low-velocity impact produces interlaminar and intralaminar failures of beams which affect their energy absorptions. The resulting energy absorptions are evaluated from force-displacement curves and subsequently discussed using assessment of loading processes and final failure modes.
\end{abstract}

\section{Keywords:}

composite, impact, pendulum, impact toughness, bending, failure mode

\section{Introduction}

With an increase of composite materials utilization in aircraft and automotive structure, they become more exposed to impacts and crashes. These include impacts of external objects, hits of pieces of stone or hailstone, bird strikes, tool impacts, collision of two vehicles or internal objects, e. g. uncontained engine debris or handgun projectiles. Therefore, the further observation of composite failure behaviour and energy absorbing capability is highly required with special attention to ply orientation and fibre architecture because of its intense ability to affect the laminate strength and cracking resistance $[1,2]$.

This paper examines this kind of property observing bending impact of unnotched specimens using pendulum testing machine. Standards describing dynamic testing which may be generally applied for testing of reinforced plastics are ASTM D6110 [3] and ASTM E2248 [4].

\footnotetext{
* Corresponding author: University of Defence in Brno, Kounicova 65, 66210 Brno, Czech Republic.E-mail: ondrej.flasar@unob.cz
} 
A very similar study is focused on comparing impact properties of both unidirectional $[0]_{12},[90]_{12},[45]_{12}$ and multidirectional $[0 / 90]_{3 \mathrm{~s}}, \quad[ \pm 45]_{3 \mathrm{~s}}, \quad\left[0 / 90 /( \pm 45)_{2}\right]_{\mathrm{s}}$ unnotched beam specimens published in [5]. The pendulum impact loads were applied on beam specimens either normal or parallel to the laminate layering. Assessing of unidirectional laminates properties shows higher impact energy absorption of $[0]_{12}$ lay-up sequence $\left(189.1 \mathrm{kJm}^{-2}\right)$ compared with other unidirectional laminates [90] 12 and $[45]_{12}\left(46.4 \mathrm{kJm}^{-2}\right.$ resp. $\left.53.1 \mathrm{kJm}^{-2}\right)$. Failure modes micrographs show a difference of the unidirectional laminates failure behaviour as well. While $[0]_{12}$ laminate shows fibre breakage and laminate delamination after impact, the unidirectional laminates $[90]_{12}$ and [45] $]_{12}$ fail in the way of fibre debonding and brittle matrix breakage. Further, the impact testing of multidirectional laminate exhibits similar energy absorption or higher comparing to the unidirectional [0] $]_{12}$ specimen. First, cross-ply laminate $[0 / 90]_{3 s}$ showed averaged energy absorption of $230 \mathrm{kJm}^{-2}$ with hybrid failure behaviour seen in cases of unidirectional $[0]_{12}$ and [90 $]_{12}$ laminates, obviously. Moreover, the angle-ply $[ \pm 45]_{3 s}$ laminate shows the best impact bending strength in terms of averaged absorbed energy which is $306.5 \mathrm{kJm}^{-2}$. This angle-ply laminate exhibits so-called pseudo-ductile behaviour, due to a pull-out effect of fibres. The fibres are pulled out of the matrix during impact loading without fibre breakage because of higher strength of fibres. In this way, fibres and matrix share the impact load and consequently absorb the highest amount of energy. The last observed quasi-isotropic laminate $\left[0 / 90 /( \pm 45)_{2}\right]_{\mathrm{s}}$ shows averaged energy absorption $265.2 \mathrm{kJm}^{-2}$. Apparently, the failure behaviour of this quasi-isotropic laminate exhibits fibre breakage, debonding and matrix cracking.

Other studies using absorbed Charpy energy to compare strength performance of different specimens observe a behaviour of nylon epoxy specimens with increasing portion of nylon [6] or influence of ceramic fillers in fabric reinforced epoxy composites [7]. Further, a study measuring properties of weft knitted fabric [8] composites is also very promising as far as a $3 \mathrm{D}$ structure of reinforcement may provide higher interlaminar shear strength. A similar way to measure fracture or impact strength is using the Izod impact pendulum instrument [9, 10], according to standard ASTM D256 [11]. Besides standardised methods, new and improved ways of determining fracture properties of composites are introduced using a striker and an instrumented incident bar impacting either beam [12] or plate [13] specimen or using computational simulations [14].

According to presented studies, this paper investigates laminates with unidirectional reinforcement in order to compare results with study [5] and uses it as a reference for laminate with woven reinforcement. Further, there were found disputable results of a laminate with woven reinforcement in [15], which should be compared with new results as well.

\section{Material and Method}

\subsection{Test Specimen}

The experimental specimens are of the unnotched beam type. The unnotched version was chosen due to observing the properties of the plain undamaged material but notch may produce a stress concentration which promotes a brittle, rather than a ductile, fracture [1]. All beam specimens are prepared from carbon fibre reinforced epoxy composite plates with fibre volume fraction $F V=60 \%$. Both the unidirectional rein- 
forcement and plain fabric were applied. The stacking sequence of both reinforcement types was used either cross-ply $[0 / 90]_{\mathrm{n}}$ or angle-ply $[ \pm 45]_{\mathrm{n}}$ throughout the whole thickness. The laminate beam specimens have the length $l=80 \mathrm{~mm}$, the width $w=$ $10 \mathrm{~mm}$ and the thickness $t=6 \mathrm{~mm}$, as illustrated in Fig. 1. The resulting span-to-width ratio is then 4.

\subsection{Impact Pendulum Test Procedure}

The impact pendulum tests were performed on Charpy device Zwick-Roell $300\left(150^{\circ}\right)$ at a room temperature. The energy of the pendulum hammer was $300 \mathrm{~J}$ and its velocity at impact point was around $5.234 \mathrm{~m} / \mathrm{s}$. The support span length was $40 \mathrm{~mm}$ and an impact force was applied normal to the unnotched laminate beam specimen (perpendicular to the laminate plane).

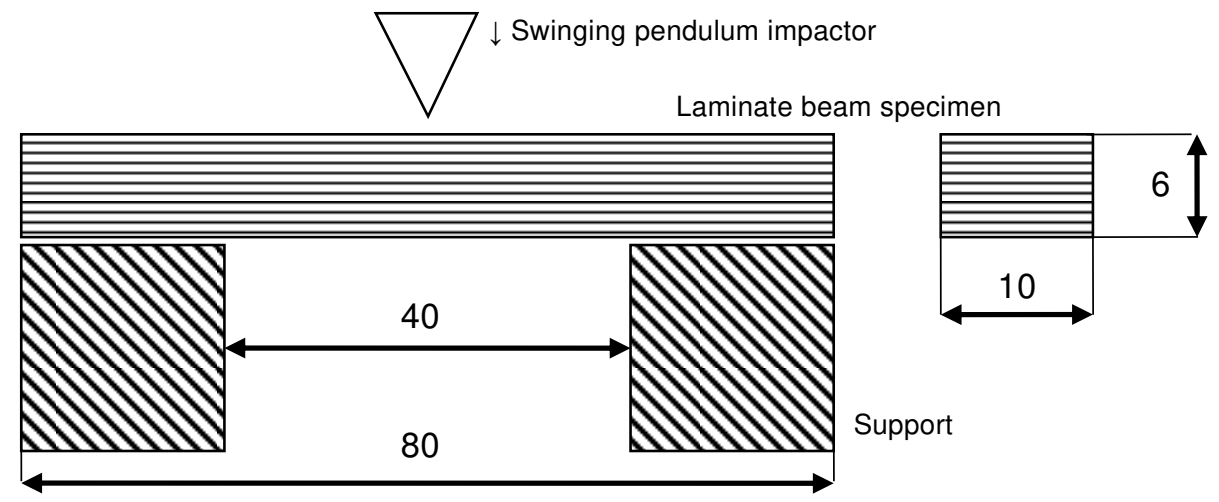

Fig. 1 Impact pendulum test layout including dimensions of laminate specimen

For the assessment of results, the whole fracture process displayed on a force-displacement curve was taken into account including both initial stage and propagation stage of the curve obtained during instrumented Charpy impact measurement. Integration of the process gives total mechanical energy absorption of the specimen $W_{t}$

$$
W_{t}=\int_{0}^{\delta} F \mathrm{~d} s,
$$

where $F$ is the applied force and $s$ is the standard travel of the hammer. It corresponds to the total energy absorption defined by the equation

$$
W_{t 2}=m g\left(h_{0}-h_{a}\right) \text {, }
$$

where $m$ is the mass of the hammer, $g$ is the gravity acceleration, $h_{0}$ is the initial height of the hammer and $h_{a}$ is the height of the hammer after impact. The absorbed energy per unit area $a_{k}\left[\mathrm{kJm}^{-2}\right]$ is then used for a better assessment and specimen comparison.

$$
a_{k}=\frac{W_{t}}{w t} .
$$

After the experiment, an optical micrograph of each broken specimen was taken using high definition digital scanner to obtain detailed images of a fractured cross-section. The images were then used for the assessment of failure mode indicating e.g. delamination, fibre pull-out or breakage, etc., together with particular crack phases 
displayed on a force-displacement curve, e. g. elastic/plastic deformation, crack propagation or unstable fracture, as defined in $[15,17]$.

\section{Results and Discussion}

Overall impact response of given CFRP system characterises various factors including matrix shear properties, fibre strength and stiffness, stacking architecture, thickness, strain rate, environmental conditions etc. A test matrix of two types of carbon reinforcement and two types of fibre orientation was set to observe comparative results obtained from pendulum impact test. In order to determine the effect of particular laminate configuration, there were monitored absorbed energies, absorbed energies per impact area, force displacement curves and failure modes. Five specimens were chosen of each configuration as a statistically satisfying amount for impact fracture property research.

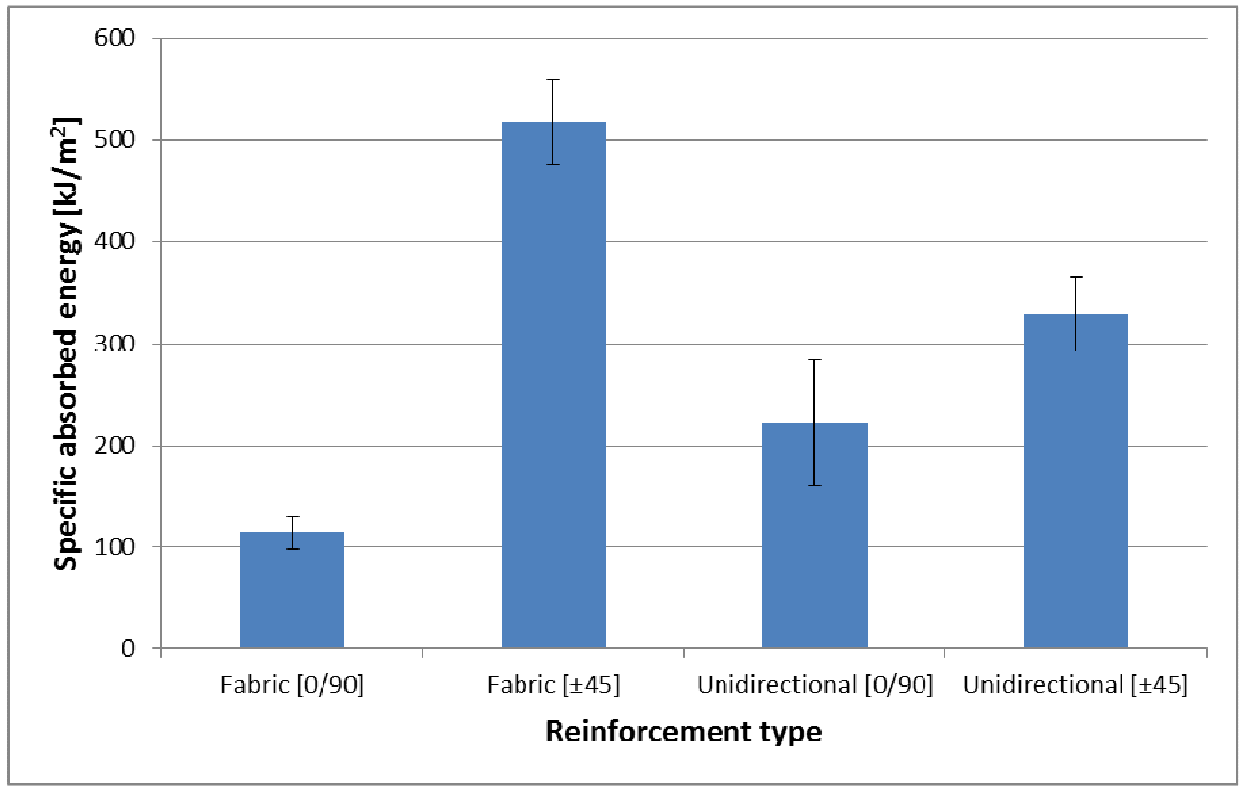

Fig. 2 Absorbed impact fracture energy of specimens with different stacking sequences including error bars

The averaged results of absorbed energy per unit area $a_{k}$ are shown in Fig. 2. When comparing fibre orientation influence, angle-ply $[ \pm 45]_{n}$ laminates reached higher absorbed energy values than cross-ply [0/90]n laminates. Namely, the highest energy absorption exhibits fabric reinforcement with angle-ply $[ \pm 45]_{\mathrm{n}}$ orientation $\left(517.7 \mathrm{kJm}^{-2}\right)$. Other angle-ply $[ \pm 45]_{\mathrm{n}}$ laminate with unidirectional reinforcement showed reduced energy absorption $\left(328.7 \mathrm{kJm}^{-2}\right)$. The reduction can be probably caused by easier fibre pull out from unidirectional laminate than from warped fabric. The cross-ply [0/90 $]_{\mathrm{n}}$ laminates showed poor results of impact toughness. The unidirectional cross-ply [0/90 $]_{\mathrm{n}}$ laminate reached about one-third $\left(221.8 \mathrm{kJm}^{-2}\right)$ and the cross-ply $[0 / 90]_{\mathrm{n}}$ fabric laminate reached less than quarter $\left(114.2 \mathrm{kJm}^{-2}\right)$ of the highest result of angle-ply $[ \pm 45]_{\mathrm{n}}$ fabric reinforced laminate. This behaviour was observed also at [5] where authors recognised very similar decrease of absorbed energy between 
unidirectional angle-ply and cross-ply laminates, as the measurements of this study have shown.

Other notion of results can be observed comparing absorbed energy at a different stage of fracture. Fig. 3 illustrates the absorption of impact energy at the point of reaching maximum impact force $F_{m}$. This point can be marked as a spot where progressive fracture initiates its growth, even if the first irreversible failure may occur earlier on the force-displacement curve, as seen in Figs. 5 to 8. The value of the absorbed energy at maximum force can be understood as an amount of energy which can be consumed by particular component producing detrimental damage without losing strength. Consequently, the absorbed energy of angle-ply $[ \pm 45]_{\mathrm{n}}$ fabric reinforced laminate shows still the highest value $\left(115.5 \mathrm{kJm}^{-2}\right)$, however, the significant scatter of results $\left( \pm 53.7 \mathrm{kJm}^{-2}\right)$ downgrades the total value very close to unidirectional angle-ply $[ \pm 45]_{\mathrm{n}}$ laminate $\left(70 \mathrm{kJm}^{-2}\right)$. Nevertheless, the scatter of the results of angle-ply $[ \pm 45]_{\mathrm{n}}$ fabric reinforced laminate is caused by irregular position of maximum force on the force-displacement curve which typically forms bench shape and the maximum force can take a position on random place (Fig. 6). Comparing the cross-ply [0/90 $]_{\mathrm{n}}$ laminate, the unidirectional cross-ply $[0 / 90]_{\mathrm{n}}$ laminate $\left(49.3 \mathrm{kJm}^{-2}\right)$ and fabric reinforced cross-ply $[0 / 90]_{\mathrm{n}}$ laminate $\left(51.3 \mathrm{kJm}^{-2}\right)$ exhibit statistically equal results.

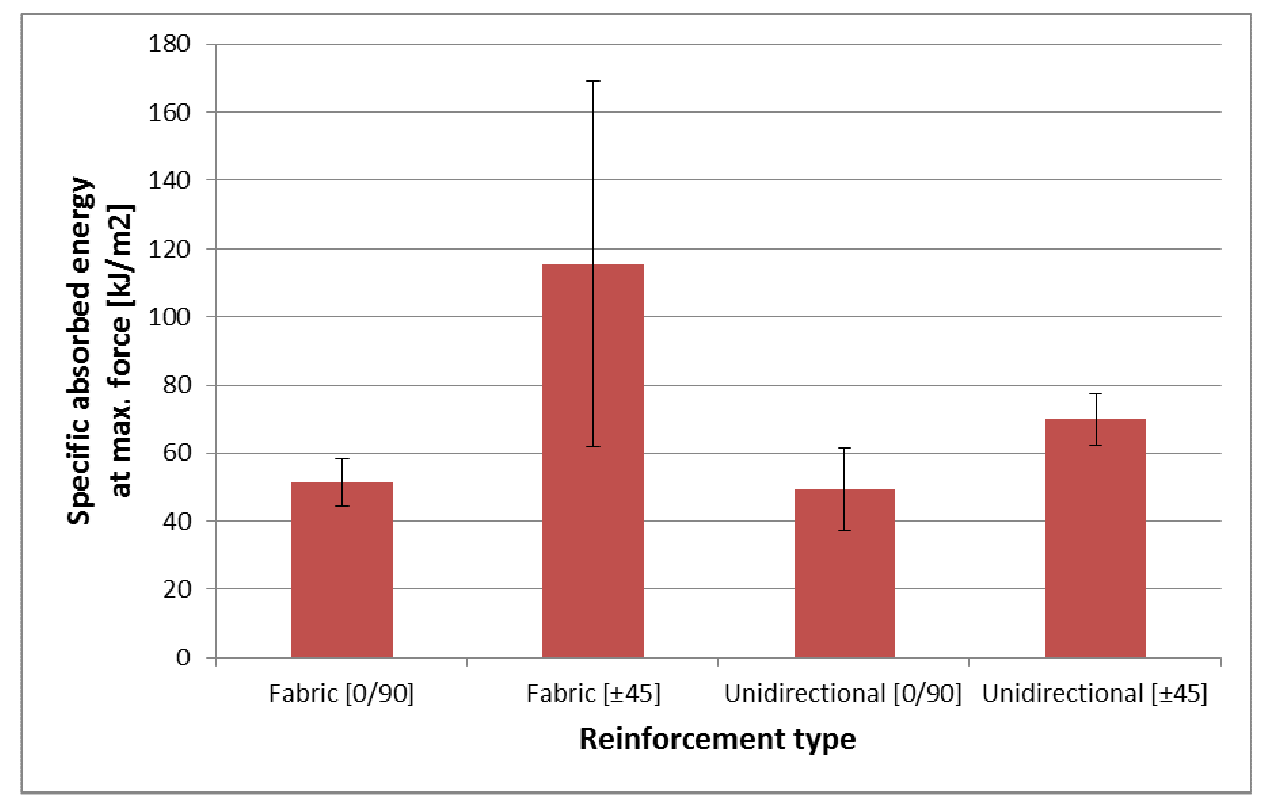

Fig. 3 Absorbed impact fracture energy at maximum reached force of specimens with different stacking sequences including error bars

Further, the significant difference between results of absorbed energy $a_{k}$ and maximum forces $F_{m}$ has to be mentioned. The averaged results of maximum forces are shown in Fig. 4. Obviously, the specimens with fibres oriented in the [0/90] direction are able to sustain higher applied forces and behave more stiff but brittle. As seen on force-displacement curves in Fig. 5 and Fig. 7 in contrast with angle-ply specimens that behave rather plastic. 


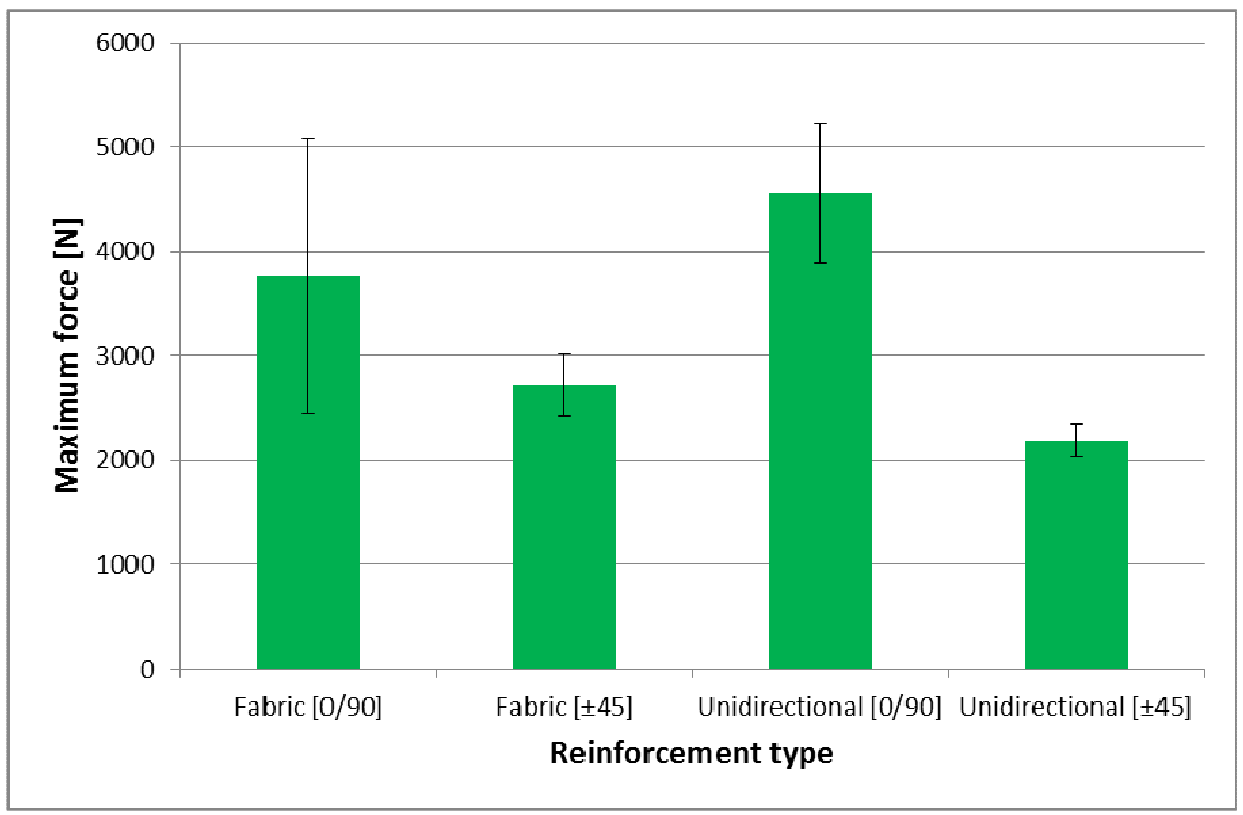

Fig. 4 Maximum force of specimens with different stacking sequences including error bars

Following the described stress assumptions, the unidirectional cross-ply [0/90]n laminate reached the highest value $(4557 \mathrm{~N})$ when slightly lower force reached fabric reinforced cross-ply [0/90]n laminate $(3763 \mathrm{~N})$. Both these cross-ply laminates exhibit notable scatter of results due to the occasional occurrence of delamination before growth to forces close to fibre breakage. Fabric reinforced angle-ply [ \pm 45$]_{n}$ laminate reached about half of the unidirectional cross-ply laminate maximum force value $(2721 \mathrm{~N})$ and unidirectional angle-ply $[ \pm 45]_{\mathrm{n}}$ laminate reached the lowest value of maximum force $(2187 \mathrm{~N})$.

As the next part of the results, representative profiles of force-displacement curves and micrographs of failure modes characterising each group of specimens are listed. Both force-displacement curves and micrographs can be used for approximate determining of failure forming during the whole load process. At the beginning of loading, there can be distinguished also low periodic waves which produce an elastic reflection of a specimen from the pendulum impactor.

Fig. 5 shows the results of fabric reinforced cross-ply $[0 / 90]_{n}$ laminate. This type of laminate produces a significant peak on the force-displacement curve which expresses very stiff increasing of force with a sudden decrease to a negligible value of force. The micrograph of the failure mode shows dominant tension fibre breakage through the whole cross section of the specimen with plain delaminations which can be marked as minor decreases on the propagation stage of the curve. This failure mode can be called brittle (or non-tough [15]).

In the second detail of failure process (Fig. 6), fabric reinforced angle-ply [ \pm 45$]_{\mathrm{n}}$ laminate results are displayed. This type of laminate exhibits a smooth bench type force-displacement curve without a distinct peak with gradual lowering to zero. This shows very firm post-failure integrity of specimen where fibres are continuously 
pulled out of the matrix after reaching the ultimate load. The process of pulling out begins on the site with maximal tension stress which means from the opposite site of the impactor application. The area near the impactor is then compressively damaged due to the compressive stresses of a bending process. The fibres are without tension fracture, which indicates that ultimate pull-out force or shear stress of matrix, respectively, is lower than fibre strength in this case. The maximum force was then multiplied by an effect of fibres pulling out of woven warp system. Such failure behaviour can be described as tough.

Fabric reinforced cross-ply $[0 / 90]_{\mathrm{n}}$ laminate $a_{k}=114.2 \mathrm{kJm}^{-2}, F_{m}=3763 \mathrm{~N}$
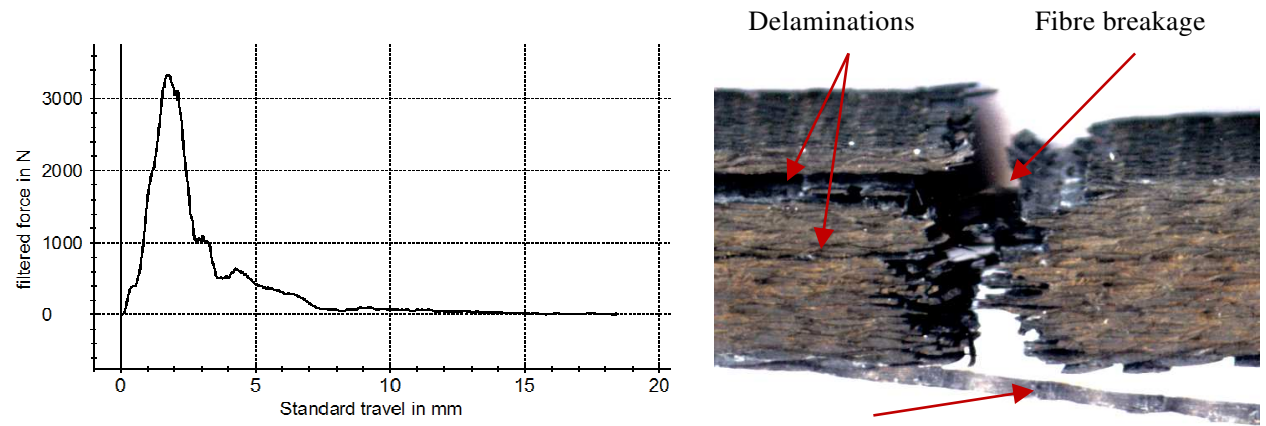

Fibre pull out

Fig. 5 Force-displacement curve and optical micrograph of carbon fabric reinforced cross-ply [0/90 $]_{\mathrm{n}}$ epoxy laminate after impact

Fabric reinforced angle-ply $[ \pm 45]_{\mathrm{n}}$ laminate $a_{k}=517.7 \mathrm{kJm}^{-2}, F_{m}=2721 \mathrm{~N}$
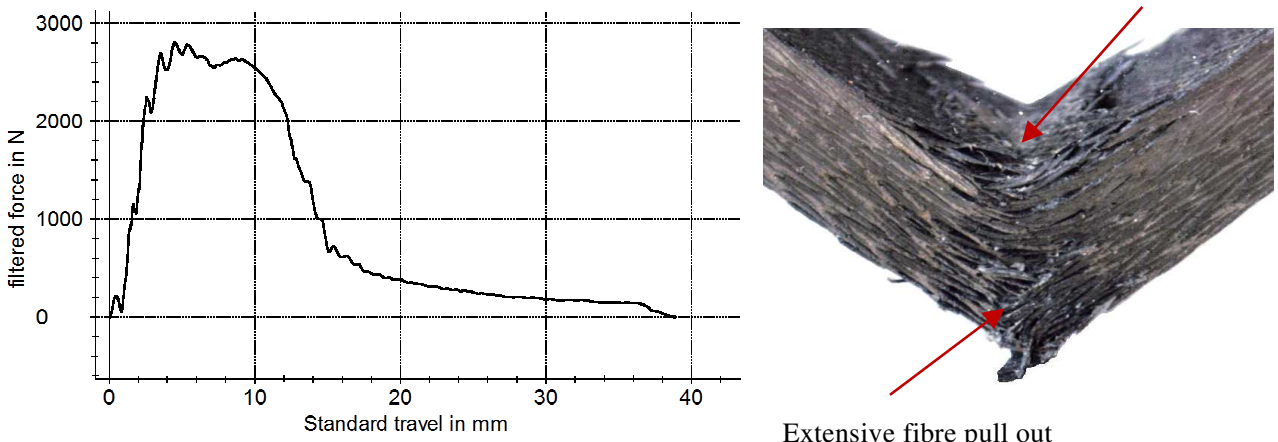

Extensive fibre pull out

Fig. 6 Force-displacement curve and optical micrograph of carbon fabric reinforced angle-ply $[ \pm 45]_{\mathrm{n}}$ epoxy laminate after impact

The next unidirectional cross-ply $[0 / 90]_{\mathrm{n}}$ laminate demonstrates volatile failure behaviour which is characterised by explosive fraying of specimen edge, see Fig. 7. Numerous delaminations and matrix breakages at $90^{\circ}$ plies are produced during this process. The force displacement curve is distinguished by a sharp force increase at the beginning of the impact. This increase points out to a very high modulus of elasticity 
in bending and high stiffness of this stacking sequence. Nevertheless, after reaching maximum force, the specimen loses majority of applied force. The created peak may indicate a brittle breaking of several surface plies away. Further loading produces increasing number of delaminations, which is displayed on the force-displacement curve as unstable proceeding to absolute strength loss but it is a proof of some post-failure integrity nevertheless. This laminate thus fails by a process which can be described as brittle and very unstable.

Unidirectional cross-ply $[0 / 90]_{\mathrm{n}}$ laminate $a_{k}=221.8 \mathrm{kJm}^{-2}, F_{m}=4557 \mathrm{~N}$

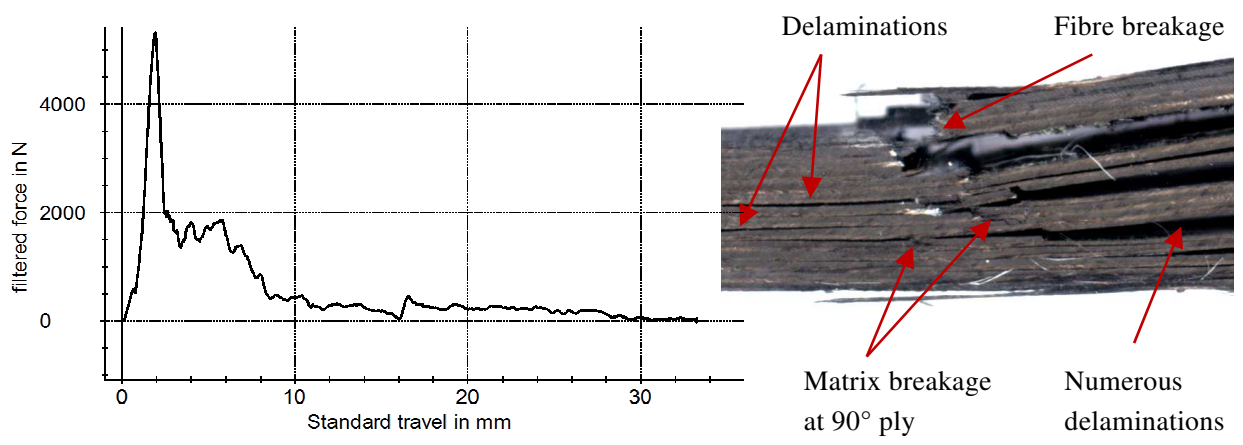

Fig. 7 Force-displacement curve and optical micrograph of unidirectional carbon fibre reinforced cross-ply $[0 / 90]_{\mathrm{n}}$ epoxy laminate after impact

Following unidirectional angle-ply $[ \pm 45]_{n}$ laminate, Fig. 8 demonstrates a plastic process of impact loading which is very similar to fabric reinforced angle-ply $[ \pm 45]_{\mathrm{n}}$ laminate. The initial stage reaches its maximum between $2 \mathrm{kN}$ and $3 \mathrm{kN}$ and about $2 \mathrm{~mm}$ displacement, as well as the fabric reinforced laminate. However, this specimen exhibits shorter bench shape after reaching the yield point than the fabric reinforced laminate. Subsequently, propagation stage shows very firm post-failure integrity during which fibres are gradually pulled out of the matrix system. Obviously, particular fibres are not so firmly held inside matrix structure than in woven fabric. The propagation stage is nevertheless more fluent than in the case of the fabric specimen and, therefore, this failure process may be called tough as well.

In this way, the unidirectional laminates keep the trend of strength and failure behaviour with results mentioned in the introduction [5], even if results obtained in this new study introduce slightly higher values. Nonetheless, the results from [19], [20] showed the same trend. All results revealed in this study and in $[5,19,20]$ are, however, in contradiction with older results published in $[15,18]$ where unidirectional cross-ply $[0 / 90]_{\mathrm{n}}$ laminate exhibits gradually decreasing trend of fracture energy with change of fibre orientation from [0/90] to [ \pm 45$]$. On the other hand, the fabric cross-ply $[0 / 90]_{\mathrm{n}}$ laminate from $[15,18]$ has the similar trend with results of this study. Although, the total values at [0/90] angle of laminate with unidirectional and fabric reinforcement are incomprehensible different in $[15,18]$ even if the volume fraction is not so different. It is assumable that any cross-ply laminate with either unidirectional or fabric reinforcement with a similar portion of fibres in both $\left(0^{\circ}\right.$ and $\left.90^{\circ}\right)$ orientations may have similar impact bending strength properties as well. In that way, this study and $[5,19,20]$ comply the premise. 
In this way, the unidirectional laminates keep the trend of strength and failure behaviour with results mentioned in the introduction [5], even if results obtained in this new study introduce slightly higher values. Nonetheless, the results from [19], [20] showed the same trend. All results revealed in this study and in $[5,19,20]$ are, however, in contradiction with older results published in $[15,18]$ where unidirectional cross-ply $[0 / 90]_{n}$ laminate exhibits gradually decreasing trend of fracture energy with change of fibre orientation from [0/90] to [ \pm 45$]$. On the other hand, the fabric cross-ply $[0 / 90]_{\mathrm{n}}$ laminate from $[15,18]$ has the similar trend with results of this study. Although, the total values at [0/90] angle of laminate with unidirectional and fabric reinforcement are incomprehensible different in $[15,18]$ even if the volume fraction is not so different. It is assumable that any cross-ply laminate with either unidirectional or fabric reinforcement with a similar portion of fibres in both $\left(0^{\circ}\right.$ and $\left.90^{\circ}\right)$ orientations may have similar impact bending strength properties as well. In that way, this study and $[5,19,20]$ comply the premise.

\section{Unidirectional angle-ply $[ \pm 45]_{\mathrm{n}}$ laminate $a_{k}=328.7 \mathrm{kJm}^{-2}, F_{m}=2187 \mathrm{~N}$}

Compression failure

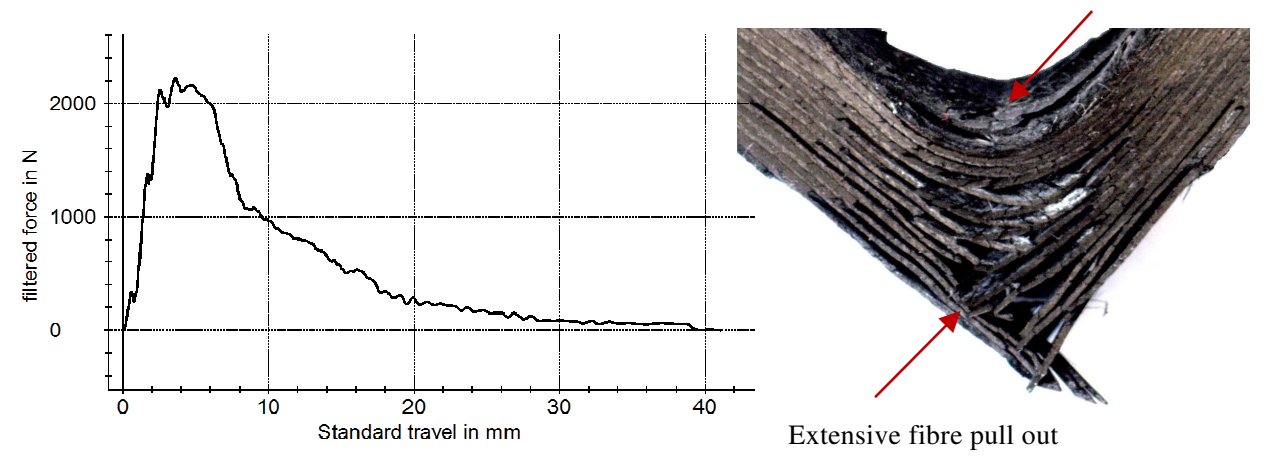

Fig. 8 Force-displacement curve and optical micrograph of unidirectional carbon fibre reinforced angle-ply $[ \pm 45]_{\mathrm{n}}$ epoxy laminate after impact

In this way, the unidirectional laminates keep the trend of strength and failure behaviour with results mentioned in the introduction [5], even if results obtained in this new study introduce slightly higher values. Nonetheless, the results from [19], [20] showed the same trend. All results revealed in this study and in $[5,19,20]$ are, however, in contradiction with older results published in $[15,18]$ where unidirectional cross-ply $[0 / 90]_{n}$ laminate exhibits gradually decreasing trend of fracture energy with change of fibre orientation from [0/90] to [ \pm 45$]$. On the other hand, the fabric cross-ply $[0 / 90]_{n}$ laminate from $[15,18]$ has the similar trend with results of this study. Although, the total values at [0/90] angle of laminate with unidirectional and fabric reinforcement are incomprehensible different in $[15,18]$ even if the volume fraction is not so different. It is assumable that any cross-ply laminate with either unidirectional or fabric reinforcement with a similar portion of fibres in both $\left(0^{\circ}\right.$ and $\left.90^{\circ}\right)$ orientations may have similar impact bending strength properties as well. In that way, this study and $[5,19,20]$ comply the premise.

Accordingly to the results, the angle-ply [ \pm 45$]$ composite beams are generally more able to absorb impact damage. This valuable fracture property is gained due to 
the low shear strength of fibre-matrix interface and fibres are thus pulled out of matrix system as described also in $[5,6,7,19,20]$. The angle-ply laminates thus present a significant feature within the field of energy absorbers and impact dampers. On the other hand, the cross-ply [0/90] laminates are more vulnerable to impact damage, but they are able to sustain the higher applied force. Therefore, the cross-ply laminates are more appropriate to strength applications only.

The fabric reinforced cross-ply [0/90] laminate typically exhibits simple brittle crack in the area of applied load. The unidirectional cross-ply [0/90] laminate behaved, however, differently due to an introduction of unidirectional $90^{\circ}$ plies. Numerous brittle matrix cracks appear in these $90^{\circ}$ plies when striker hits the beam specimen. The mechanisms of impact matrix cracking are also described in $[15,18,21]$. A similarity can be found also in cracking of TiGr specimen composed of $0^{\circ}$ unidirectional CFRP plies and titanium plates [22] where CFRP plies fail, obviously, in fibre breakage mode and Ti plies fail brittle just like $90^{\circ}$ plies in the cross-ply laminate. The $90^{\circ}$ plies also enable an easier delamination of particular $0^{\circ}$ plies and explosive fraying of a specimen is then formed as described above.

\section{Conclusion}

The impact toughness, failure mode and crack propagation of the CFRP with different stacking sequences were determined in this study. The instrumented Charpy impact test using Zwick-Roell 300 provided accurate measurement of these properties. The tested fibre material was carbon cured by epoxy resin due to its exclusive representation in the aircraft industry. The following points summarise the presented study:

- The approach combines carbon fibre epoxy systems with different layup architecture to determine its influence on the impact toughness.

- Fracture process obtained on force-displacement curve and its significant points has been assessed together with failure modes of particular specimen.

- Assessment of results showed that there are different ways for achieving higher impact force and higher impact toughness.

- For higher impact toughness, angle-ply composites with fibres oriented in $\pm 45^{\circ}$ which behave in a more plastic way due to shear fibres pulling out of matrix without breaking them are suitable.

- For higher force, cross-ply composites with fibres oriented mainly in $0^{\circ}$ direction which provide higher strength and stiffness are suitable.

- The fabric reinforcement is slightly better in the use of impact resistance than unidirectional reinforcement.

\section{References}

[1] GRADY, J. Fracture Toughness Testing of Polymer Matrix Composites [Technical report]. NASA-TP-3199, USA, 1992.

[2] NIU M.C.Y. Composite Airframe Structures. Hong Kong: Conmilit, 1992.

[3] ASTM D6110-10, Standard Test Method for Determining the Charpy Impact Resistance of Notched Specimens of Plastics. ASTM International, 2010.

[4] ASTM E2248-15, Standard Test Method for Impact Testing of Miniaturized Charpy V-Notch Specimens. ASTM International, 2015. 
[5] CAMINERO, M.A., RODRÍGUEZ, G.P. and MUÑOZ, V. Effect of Stacking Sequence on Charpy Impact and Flexural Damage Behavior of Composite Laminates. Composite Structures, 2016, vol. 136, p. 345-357. ISSN 0263-8223. DOI 10.1016/j.compstruct.2015.10.019.

[6] KIM, K.W. et al. Cure Behaviors and Mechanical Properties of Carbon Fiberreinforced Nylon6/epoxy Blended Matrix Composites. Composites Part B: Engineering, 2017, vol. 112, p. 15-21. ISSN 1359-8368. DOI $10.1016 / \mathrm{j}$. compositesb.2016.12.009.

[7] AHMED, K.S., MALLINATHA, V. and AMITH, S.J. Effect of Ceramic Fillers on Mechanical Properties of Woven Jute Fabric Reinforced Epoxy Composites. Journal of Reinforced Plastics and Composites, 2011, vol. 30, no. 15, p. 1315-1326. ISSN 0731-6844. DOI 10.1177/0731684411420606.

[8] HASANI, H., AJELI, S., HESSAMI, R. and ZADHOUSH, A. Investigation into Energy Absorption Capacity of Composites Reinforced by Three-dimensionalweft Knitted Fabrics. Journal of Industrial Textiles, 2014, vol. 43, no. 4, p. 536548. ISSN 1528-0837. DOI 10.1177/1528083712468604.

[9] KAVITHA, N., BALASUBRAMANIAN, M. and KENNEDY, A.X. Investigation of Impact Behavior of Epoxy Reinforced with Nanometer- and micrometersized Silicon Carbide Particles. Journal of Composite Materials, 2013, vol. 47, no. 15, p. 1877-1884. ISSN 0021-9983. DOI 10.1177/0021998312451920.

[10] ASOPA, V. et al. A Comparative Evaluation of Properties of Zirconia Reinforced High Impact Acrylic Resin with that of High Impact Acrylic Resin. The Saudi Journal for Dental Research, 2015, vol. 6, no. 2, p. 146-151. ISSN 2352-0035. DOI 10.1016/j.sjdr.2015.02.003.

[11] ASTM D256-10e1, Standard Test Methods for Determining the Izod Pendulum Impact Resistance of Plastics. ASTM International, 2010.

[12] WEISBROD, G. and RITTEL, D. A Method for Dynamic Fracture Toughness Determination using Short Beams. International Journal of Fracture, 2000, vol. 104, no. 1, p. 89-103. ISSN 0376-9429. DOI 10.1023/A:1007673528573.

[13] DE CICCO, D., ASAEE, Z. and TAHERI, F. Low-velocity Impact Damage Response of Fiberglass / Magnesium Fiber-metal Laminates under Different Size and Shape Impactors. Mechanics of Advanced Materials and Structures, 2017, vol. 24, no. 2, p. 545-555. ISSN 1537-6494. DOI 10.1080/15376494. 2016.1162343.

[14] XU, W. and WAAS, A.M. Fracture Toughness of Woven Textile Composites. Engineering Fracture Mechanics, 2017, vol. 169, p. 184-188. ISSN 0013-7944. DOI 10.1016/j.engfracmech.2016.11.027.

[15] HARRIS, B. Engineering Composite Materials. London: Institute of Metals, 1999.

[16] TRONSKAR, J.P., MANNAN, M.A. and LAI, M.O. Measurement of Fracture Initiation Toughness and Crack Resistance in Instrumented Charpy Impact Testing. Engineering Fracture Mechanics, 2002, vol. 69, no. 3, p. 321-338. ISSN 0013-7944. DOI 10.1016/S0013-7944(01)00077-7.

[17] HART, K.R. and WETZEL, E.D. Fracture Behavior of Additively Manufactured Acrylonitrile Butadiene Styrene (ABS) Materials. Engineering Fracture Mechan- 
ics, 2017, vol. 177, p. 1-13. ISSN 0013-7944. DOI 10.1016/j.engfrac mech.2017.03.028.

[18] HARRIS, B. Micromechanisms of Crack Extension in Composites. Metal Science, 1980, vol. 14, no. 8-9, p. 351-362. ISSN 0306-3453. DOI 10.1179/ msc.1980.14.8-9.351.

[19] TOMITA, Y. and MORIOKA. K. Effect of Lay-up Sequence on Mechanical Properties and Fracture Behaviour of Advanced CFRP Laminate Composite. Materials Science and Engineering: A, 1997, vol. 234-236, p. 778-781. ISSN 0921-5093. DOI 10.1016/S0921-5093(97)00411-5.

[20] MORIOKA, K. and TOMITA, Y. Effect of Lay-up Sequence on Mechanical Properties and Fracture Behaviour of CFRP Laminate Composites. Materials Characterization, 2000, vol. 45, no. 2, p. 125-136. ISSN 1044-5803. DOI 10.1016/S1044-5803(00)00065-6.

[21] RICHARDSON, M.O.W. and WISHEART, M.J. Review of Low-velocity Impact Properties of Composite Materials. Composites Part A: Applied Science and Manufacturing, 1996, vol. 27, no. 12, p. 1123-1131. ISSN 1359-835X. DOI 10.1016/1359-835X(96)00074-7.

[22] TARPANI, J.R., MALUF, O. and GATTI, M.C.A. Charpy Impact Toughness of Conventional and Advanced Composite Laminates for Aircraft Construction. Materials Research, 2009, vol. 12, no. 4, p. 395-403. ISSN 1516-1439. DOI 10.1590/S1516-14392009000400004. 